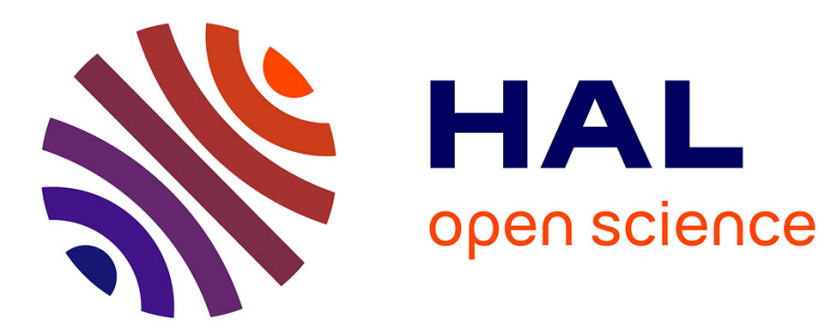

\title{
Synergic toxic effects of food contaminant mixtures in human cells
}

Benjamin Kopp, Pascal Sanders, Imourana Alassane-Kpembi, Valérie Fessard, Daniel Zalko, Ludovic Le Hégarat, Marc Audebert

\section{To cite this version:}

Benjamin Kopp, Pascal Sanders, Imourana Alassane-Kpembi, Valérie Fessard, Daniel Zalko, et al.. Synergic toxic effects of food contaminant mixtures in human cells. Mutagenesis, 2020, 35 (5), pp.415424. 10.1093/mutage/geaa019 . hal-02927206

\section{HAL Id: hal-02927206 https: / hal.inrae.fr/hal-02927206}

Submitted on 31 May 2021

HAL is a multi-disciplinary open access archive for the deposit and dissemination of scientific research documents, whether they are published or not. The documents may come from teaching and research institutions in France or abroad, or from public or private research centers.
L'archive ouverte pluridisciplinaire HAL, est destinée au dépôt et à la diffusion de documents scientifiques de niveau recherche, publiés ou non, émanant des établissements d'enseignement et de recherche français ou étrangers, des laboratoires publics ou privés. 
3 Benjamin Kopp ${ }^{1,3}$, Pascal Sanders ${ }^{3}$, Imourana Alassane-Kpembi ${ }^{1,2}$, Valérie Fessard ${ }^{3}$, Daniel Zalko ${ }^{1}$, $4 \quad$ Ludovic Le Hégarat ${ }^{3} \&$ Marc Audebert ${ }^{1, *}$

$6{ }^{1}$ Toxalim, INRAE, INP-ENVT, INP-EI-Purpan, Université de Toulouse 3 Paul Sabatier, Toulouse, 7 France

$8 \quad{ }^{2}$ Hôpital d'Instruction des Armées, Camp Guézo, 01BP517 Cotonou, Bénin.

$9 \quad{ }^{3}$ ANSES (French Agency for Food, Environmental and Occupational Health \& Safety), Toxicology 10 of Contaminants Unit, Fougères, France

Running title: Genotoxic and mutagenic synergies of food contaminants. 


\section{Abstract}

22

Humans are exposed to multiple exogenous substances, notably through food consumption. Many of these compounds are suspected to impact human health, and their combination could exacerbate their harmful effects. We previously observed in human cells that, among the six most prevalent food contaminant complex mixtures identified in the French diet, synergistic interactions appeared in two mixtures compared to the response with the chemicals alone. In the present study we demonstrated in human cells that these properties are driven only by two heavy metals in each mixture: tellurium (Te) with cadmium $(\mathrm{Cd})$, and $\mathrm{Cd}$ with inorganic arsenic (As), respectively. It appeared that the predicted effects for these binary mixtures using the mathematical model of Chou and Talalay confirmed synergism between these heavy metals. Based on different cell biology experiments (cytotoxicity, genotoxicity, mutagenesis, DNA repair inhibition experiments), a detailed mechanistic analysis of these two mixtures suggests that concomitant induction of oxidative DNA damage and decrease of their repair capacity contribute to the synergistic toxic effect of these chemical mixtures. Overall, these results may have broad implications for the fields of environmental toxicology and chemical mixture risk assessment.

Keywords: food contaminants; mixtures; interactions; genotoxicity; H2AX; mutagenesis. 


\section{Introduction}

Co-exposure to a broad range of chemicals contained in food has been demonstrated in several reports (1-3). Heavy metals, polycyclic aromatic hydrocarbons (PAHs), pesticides, mycotoxins and other xenobiotics can contaminate food. Their combined effects should be taken into account to correctly address public health concern (4). Chemical risk assessment is traditionally carried out on a chemical-by-chemical basis, thereby disregarding possible combined effects. In western countries, most contaminants of concern are detected at low doses in foodstuff (5), but this does not mean that there are no effect resulting from their interaction in mixture. The term interaction is defined as a situation in which some or all individual components of a mixture influence each other's toxicity, and where the combined effects of these components differ from the predicted additive effects (6). The global assessment of the toxicity of mixtures deserves particular attention and is indispensable for a more realistic risk assessment of food contaminants (7). Still, assessing the risk of human coexposure to multiple chemicals poses several challenges (e.g. which chemical included, proportion of each compound, technique used, mathematical modelling) to scientists, risk assessors and regulatory authorities worldwide (8-10).

In recent decades, the general assumption is that substances inside a mixture do not interact. The combined effect in mixture can then be assessed using two main mathematical concepts: Concentration Addition (CA), also called Loewe additivity (11), and Independent Action (IA), also called Bliss independence (12). These reference models used to estimate the expected toxicity (generally cytotoxicity) of a mixture were based on toxicological data concerning each individual compound and its respective concentration in the mixture $(13,14)$. The two additivity models provide mainly conservative predictions of cumulative effects $(9,15)$. Indeed, when data on mixtures deviate from the predictions provided by the CA and IA models, sub-additivity (i.e. antagonism) and supra-additivity (i.e. sensitization or synergism) can be suspected $(8,16-18)$. Even though it has been concluded from the existing literature that interactions are a rare phenomenon compared to a 
dose or response additivity $(19,20)$, appropriate methods should be developed to incorporate the occurrence of such interactions in the risk assessment of mixtures $(5,21)$. Several studies reported the occurrence of synergistic interactions $(22,23)$ and models like CA or IA showed limitations to predict mixture effects in some particular scenarios (24). Therefore, supra-additivity, which mainly occurs through synergistic mechanisms, is a key concern for risk assessors as it is crucial to provide a quantitative contribution of each compound involved in a synergistic interaction to the toxicity of a mixture (25).

In a previous work, we observed that two mixtures of food contaminants present in the French diet were genotoxic and mutagenic in HepG2 and HepaRG cells $(26,27)$. Furthermore, the genotoxic and cytotoxic effects observed with these two mixtures, suggested some degree of interaction between the compounds. Therefore, to reach more confidence in the evaluation of toxicological effects of mixtures, in the present study we conducted an extensive functional analysis to (i) identify which substances drive the toxicity of these mixtures using the genotoxic $(\gamma \mathrm{H} 2 \mathrm{AX})$ and mutagenic (PIG-A) endpoints in a "reduced approach"; (ii) assess their combined effects in terms of additive, antagonistic or synergistic toxicity using the combination index (CI) isobologram method from Chou-Talalay and (iii) identify the mechanisms involved in the observed synergistic toxic effects. 
Chemical and reagents. Penicillin, streptomycin, trypsin, PBS, RNAse, DMSO and Triton X-100 were purchased from Sigma-Aldrich. The blocking solution (MAXblock Blocking Medium) was purchased from Active Motif (Belgium). CF770 antibody (goat anti-rabbit and anti-mouse antibodies) and RedDot2 were purchase from Biotium (Hayward, CA, USA). Mouse anti-human CD59 (Protectin) APC monoclonal antibody was purchased from Affymetrix (eBioscience, USA). FLAER: Alexa fluor 488 proaerolysin was purchase from Cedarlane (CA).

Culture of HepG2 cells. HepG2 human hepatoblastoma cells (ATCC $\mathrm{N}^{\circ} \mathrm{HB}-8065$ ) were routinely grown in $75-\mathrm{cm}^{2}$ culture flasks in $\alpha$ MEM medium supplemented with $10 \% \mathrm{FBS}, 100 \mathrm{U} \mathrm{mL}^{-1}$ penicillin and $100 \mu \mathrm{g} \mathrm{mL}^{-1}$ streptomycin. Cultures were maintained in a humidified atmosphere with $5 \% \mathrm{CO}_{2}$ at $37^{\circ} \mathrm{C}$ and the medium was refreshed every 2-3 days.

\section{Reduced approach in HepG2 cells}

Mixture treatments. All compounds (purity > 95\%) were purchased from Sigma-Aldrich. Depending on their solubility, compounds were dissolve either in pure water (EMD Millipore) or in dimethyl sulfoxide (DMSO) as previously described. As detailed in our previous papers $(26,27)$, depending on their solubility, each compound was first dissolved either in pure water or in DMSO, hereafter referred to the "DMSO phase" and the "water phase". DMSO-phase contained uniquely the organic compounds and water-phase contained uniquely heavy metals. Full mixtures were prepared from these two sub-mixtures. Each mixture was prepared with chemicals by taking into account their calculated proportion in the French diet. Cells were treat for $24 \mathrm{~h}$. The positive control was $0.3 \mu \mathrm{M}$ benzo[a]pyrene (BaP) (DNA adduct) or $2.5 \mu \mathrm{M}$ menadione (MD) (oxidative DNA damage inducer). All the experiments were run at least three times independently. The mixtures identified previously contain different heavy metals. This particular outcome raised the question for the choice of the heavy metal specifications and showed a limitation to the mixture scenarios. 
Therefore, in our previous study, one or several specification(s) were examined for each heavy metal, and the choice of the specification was based on the genotoxicity potential (28).

Combination of different heavy metal mixtures. Six different combinations (A, B, C, D, E and F) of heavy metals per mixture were tested at $100 \mu \mathrm{M}$, always in proportion reflecting their detection in the French diet. A "reduced" approach was tested by removing the heavy metals one by one per mixture (supplementary Data 1 and 2). According to the results observed, binary mixtures were designed to predict effect in each situation. It should be note that the proportion value of each heavy metal in each situation was always in conformity with mixtures identified previously (4).

In-Cell Western $\gamma \mathbf{H} 2 \mathrm{AX}$ assay. The in-cell western (ICW) technique was perform as previously described (29-33). For the quantification of the genotoxicity, fluorescent intensity for $\gamma \mathrm{H} 2 \mathrm{AX}$ per cell (as determined by the fluorescent intensity for $\gamma \mathrm{H} 2 \mathrm{AX}$ divided by the fluorescence intensity for DNA content) was divided by the respective value for negative and expressed as a fold change. Cell viability was indicated by relative cell count $[\mathrm{RCC}$ or final cell count (treated)/final cell count $($ control $) \times 100]$. A mixture was considered positive in the $\gamma \mathrm{H} 2 \mathrm{AX}$ test if three criteria were achieved as previously reported: (1) at last one of the test concentrations induced a reproducible 1.3 -fold increase in $\gamma \mathrm{H} 2 \mathrm{AX}$, (2) the increase was statistically significant (Student's test) compared with the concurrent solvent control, and (3) the level of cytotoxicity was below 50\% compared to solvent control.

ROS quantification. Reactive oxygen species (ROS) were quantified using a CM- $\mathrm{H}_{2} \mathrm{DCFDA}$ fluorescent probe as indicated by manufacturer (Thermo Scientific, Waltham, MA, USA). To confirm the role of oxidative stress, cells were either pre-treated with $150 \mu \mathrm{M}$ of buthionine-(S, R)sulfoximine (BSO) an inhibitor of glutathione biosynthesis for $16 \mathrm{~h}$ or co-treated with $5 \mathrm{mM}$ of $\mathrm{N}$ acetylcysteine (NAC) an antioxidant for $24 \mathrm{~h}$, and $\mathrm{CM}-\mathrm{H}_{2}$ DCFDA was quantified in cell and 
expressed as a fold increase compared to untreated cells (i.e. without any mixture treatments but with BSO or NAC).

In vitro mutagenicity study with the PIG-A assay. In vitro mutagenicity was investigated with the PIG-A assay as previously described (27). Mutant frequencies was calculate as the number of GPI (-) cells divided by the number of total living cells analyzed and expressed as a fold change. Following OECD guidelines, cytotoxicity was defined as relative cloning efficiency (RCE) obtained at the time of mutation selection and relative survival (RS) $(\mathrm{RS}=\mathrm{RCE}($ test $) / \mathrm{RCE}($ control)). $\mathrm{A}$ mutagenic effect was considered to have occurred if the treatment resulted in a RS > $10 \%$ and the induction of PIG-A mutants was at least statistically 2-fold higher than in the control.

Dose-response relationships of the individual heavy metals. Viability was transform into cytotoxicity values (eq. 1):

$$
\text { Cytotoxicity }(\%)=100-\text { viability }(\%), \quad(\text { eq } 1)
$$

The Hill model determined the concentration-response relationships of the individual heavy metals. To normalize the effects, the bottom and top asymptotes were set to $0 \%$ and $100 \%$ respectively. Cytotoxicity values superior to 100 or inferior to 0 were set to 100 or 0 , respectively. The experimental data set was fitted to the Hill function (eq 2)

$$
E(\%)=\frac{100}{1+\left(\frac{c}{E C 50}\right)^{-p}}, \quad(e q 2)
$$

Where $E$ is the effect in $\%, c$ is the concentration of the test agent $(\mu \mathrm{M}), p$ the parameter slope and $E C_{50}$ the concentration of the single agent that produces a $50 \%$ effect. For each concentrationresponse curve, a non-linear sigmoid regression analysis was draw on GraphPad Prism 4.0 (GraphPad Software, Inc.). 

relationships of the individual and combined binary heavy metals were biometrically modeled using the median-effect equation of the mass action law (34).

C concentration of the heavy metal

$f_{\mathrm{a}} \quad$ fraction affected by $\mathrm{D}$

$f_{\mathrm{u}} \quad$ fraction unaffected (i.e., $\left.f \mathrm{u}=1-f \mathrm{a}\right)$

$D_{\mathrm{m}} \quad$ median-effect dose (e.g., EC50)

$m \quad$ coefficient signifying the shape of the dose-effect relationship

( $m=1, m>$ and $m<1$ indicate hyperbolic, sigmoidal, and flat sigmoidal dose-effect curves, respectively)

$$
n(C I)_{x}=\frac{\left(D_{x}\right)_{1-n}\left\{\frac{[D]_{j}}{\Sigma^{n}[D]}\right\}}{\left(D_{m}\right)_{j}\left\{\frac{\left(f a_{x}\right)_{j}}{\left[1-\left(f a_{x}\right)_{j}\right]^{1 / m j}}\right\}}
$$

Where ${ }^{n}(C I)_{x}$ is the combination index for $n$ drugs at $x \%$ inhibition, $\left(D_{x}\right)_{1-n}$ is the sum of the dose of $\mathrm{n}$ drugs that exerts $\mathrm{x} \%$ inhibition in combination, $\left([\mathrm{D}]_{\mathrm{j}} / \sum^{\mathrm{n}}[\mathrm{D}]\right)$ is the proportionality of the dose of each drugs that exerts $x \%$ inhibition in combination, and $\left(D_{m}\right)_{j}\left[\left(f a_{x}\right)_{j} /\left(1-f a_{x}\right)_{j}\right]^{1 / m j}$ is the dose of each drug alone that exerts $\mathrm{x} \%$ inhibition.

$\mathrm{CI}<1,=1$ and $>1$ indicates synergism, additive effect and antagonism, respectively. For all toxic combinations, CI values were generated over a range of fractions of cell viability affected (fa) from $0.05-0.95$ (5-95\% toxicity). 
Dose reduction indices (DRI) were calculated for all mixtures with synergistic toxicity. The dose reduction index (DRI) measures by how many fold the dose of each compound in a synergistic combination can be reduced. DRIs can be obtained from the reciprocal of each term of the CI equation(35):

$$
\begin{aligned}
& \qquad \begin{array}{ll}
n(C I)_{x} & =\sum_{j=1}^{n} \frac{(D)_{i}}{(D x)_{j}}=\sum_{j=1}^{n} \frac{1}{(D R I)_{j}} \\
\text { and } \quad & (D R I)_{1}=\frac{\left(D_{x}\right)_{1}}{(D)_{1}},(D R I)_{2}=\frac{\left(D_{x}\right)_{2}}{(D)_{2}} \ldots, \text { etc }
\end{array}
\end{aligned}
$$

Analysis of the dose-effect relationship for the toxicity of individual compound and mixtures, calculation of CI values and their $95 \%$ confidence intervals, the fraction affected-combination index (Fa-CI) plots for combined effects were all performed using Compusyn software version 3.0.1 (ComboSyn Inc., Paramus, NJ, USA).

Statistics. All experiments were run at least three times independently. Statistically significant increases or decreases in $\gamma \mathrm{H} 2 \mathrm{AX}, \mathrm{CM}-\mathrm{H}_{2} \mathrm{DCFDA}$, PIG-A frequencies were compared with controls using Student's test in Excel 2016 software $(* p<0.05 ; * * p<0.01$; ***p $<0.001)$. Error bars represent SEM (standard error of the mean). In some cases, a one-way ANOVA was perform to compare three or more independent samples. This test was followed by a post hoc Tukey's multiple comparison test using GraphPad Prism 4.0 (GraphPad Software, Inc.) (*p<0.05; **p< 0.01; ***p $<0.001)$. Finally, a two-way ANOVA was used to compare the interaction effect for each group of treatments, followed by a Bonferroni post-test using GraphPad Prism 4.0 (GraphPad Software, Inc.) $(a, p<0.05 ; b, p<0.01 ; c, p<0.001)$. 


\section{Identification of mixture components with genotoxic effects}

187

188

189

190

191

192

193

194

195

196

197

198

199

200

201

202

203

204

205

206

207

208

Genotoxicity and cytotoxicity of sub-mixtures. The genotoxic and cytotoxic potential of the whole mixtures in HepG2 cells were compared to that of their respective DMSO and water phase submixtures, using the ICW $\gamma \mathrm{H} 2 \mathrm{AX}$ assay (36) (Figure 1). The water phase contained only heavy metals solubilized in sterile water whereas the DMSO phase contained only non-polar chemicals like HAPs, mycotoxins, as detailed previously $(26,27)$. We observed that the genotoxicity of both whole M1 and M3 mixtures was exclusively linked to their water phase, while their DMSO phase had no toxic effect. Indeed, M1 produced a significant induction (1.6-fold) of $\gamma \mathrm{H} 2 \mathrm{AX}$ at $100 \mu \mathrm{M}$, similar to the response with the water phase (1.4-fold induction) whereas no significant induction of $\gamma \mathrm{H} 2 \mathrm{AX}$ was observed with the DMSO phase of M1 (0.8-fold induction) (Figure 1a). Similarly, whole M3 mixture and its water phase were clearly positive for $\gamma \mathrm{H} 2 \mathrm{AX}$ whereas the DMSO phase was not genotoxic (Figure 1b). Similar observations were drawn from the cell viability data (Figures 1a and 1b). In conclusion only heavy metals present in water phases could account for the observed toxic effects of the whole mixtures.

Genotoxicity and cytotoxicity of heavy metal combinations. As only the water phases of M1 and M3 were found to be genotoxic, we used a "reduced approach" by testing modified water phases of each mixture (Supporting Information Appendix 1 and 2), to identify which heavy metal were responsible of the observed effects. The genotoxicity of the M1 and M3 water phases were tested in all possible scenarios in which one of the six heavy metal of each mixture was removed. Results were compared with those obtained with the whole mixtures (DMSO and water phases together) (Figure 2; Appendix 3). Comparison of the different heavy metal combinations with corresponding mixtures were detailed at genotoxic and cytotoxic relevant concentrations, i.e. 100 and $250 \mu \mathrm{M}$, respectively. In the absence of cadmium (Cd) or tellurium (Te), no genotoxicity was detect for the 
M1 water phase (Figure 2a). Moreover, a detailed analysis of the cell viability data (\% RCC) indicated that mixtures without Te or Cd were also less cytotoxic than the whole mixture (Appendix 3a). Results for M3 indicated that only arsenic (As) was related to a decrease in $\gamma \mathrm{H} 2 \mathrm{AX}$ induction (Figure 2b) and that only Cd was involved in the cytotoxicity of the mixture (Appendix 3b). The effects of only binary mixtures of the suspected metals involved in toxic effects were also examined (Figure 2 c-d). No significant difference in the induction of $\gamma \mathrm{H} 2 \mathrm{AX}$ between the whole mixtures and the binary mixtures of the heavy metals was observed. Notably, when the two-suspected heavy metals ( $\mathrm{Cd}$ and $\mathrm{Te}$ ) were excluded from mixture M1, no DNA damage was observed, confirming that the genotoxic potential of the mixture 1 was driven by the presence of these two heavy metals (Figure 2c). With the cytotoxicity data, we observed that $\mathrm{Cd}$ with $\mathrm{As}$ in $\mathrm{M} 3$ were the drivers of the toxicity of the corresponding mixture (Figure 2d).

Mutagenicity of the binary mixtures of driver chemicals. Our previous study indicated that in vitro, M1 and M3 whole mixtures induced mutagenicity in the HepG2 PIG-A assay (27). Here we investigated if the mutagenicity of these mixtures was also due to the presence of Cd-Te in M1 and Cd-As in M3. The background level of GPI (-) frequency was $47 \pm 9$ GPI (-) cells / $10^{6}$ viable HepG2 cells. The positive control $(\mathrm{BaP} 1 \mu \mathrm{M})$ induced a statistically significant fold 2.2 fold $(\mathrm{P} \leq$ 0.001) (data not showed). Regarding the dose-response of mutant GPI (-) cell frequency and the LOEC (lowest observed effect concentration), the results obtained with the whole M1 and M3 mixtures were comparable to those obtained with only the corresponding binary heavy metals (Table 1). Notably, M1 at $150 \mu \mathrm{M}$ induced a 2.89-fold induction of PIG-A mutant phenotype cells versus a 2.75-fold induction for the binary Cd-Te mixture, and $\mathrm{M} 3$ at $30 \mu \mathrm{M}$ induced a 2.61-fold versus 2.03-fold for the binary As-Cd mixture, implicating these heavy metals in the observed mutagenic effects. We noted however, that at higher concentration, whole mixture of M3 presented a greater genotoxic and cytotoxic effect than binary As/Cd mixture (Table 1). 


\section{Assessment of the combined toxic effects}

Individual cytotoxicity of As, Cd and Te. HepG2 cells were exposed for $24 \mathrm{~h}$ to As, Cd and Te. The concentration-response cytotoxicity curves were fitted using the Hill model (Appendix 4). The three heavy metals showed a concentration-dependent cytotoxic effect and were ranked as follows: Cd $\left(\mathrm{EC}_{50}: 63.9 \mu \mathrm{M}\right)>\mathrm{As}\left(\mathrm{EC}_{50}: 73.1 \mu \mathrm{M}\right)>\mathrm{Te}\left(\mathrm{EC}_{50}: 592.1 \mu \mathrm{M}\right)$

Combined cytotoxicity of $\mathrm{As}, \mathrm{Cd}$ and Te. The next step was to determine the type of interaction (additivity, synergy or antagonism) between these heavy metals. The ratios between the heavy metals were chosen to obtain an equivalent proportion reflecting their detection in the French diet (i.e. M1: $(\mathrm{Cd}+\mathrm{Te}[0.85: 0.25])$ and $\mathrm{M} 3:(\mathrm{As}+\mathrm{Cd}[0.73: 0.27]))$. The types of interactions were analyzed using the Chou-Talalay method (37). Combination index (CI) values were calculated for a wide range of cytotoxicity levels (from $10 \%$ to $100 \%$ ) using experimental data for $\mathrm{As}, \mathrm{Cd}$ and Te alone (Figure $3 \mathbf{a}-\mathbf{b}$ ). We observed that the interaction between the main drivers of the mixtures demonstrated a very strong synergism $(\mathrm{CI}<1)$ at all the concentrations tested ( $\mathrm{fa}$ between 5-95\%). In order to quantify the synergy between heavy metals, dose reduction index (DRI) was calculated for all level of cytotoxicity (Appendix 5). This latter parameter indicated notable dose reduction in all conditions. Fifteen fold less $\mathrm{Cd}$ and 60 -fold less Te were required to reach the observed $50 \%$ cytotoxicity of M1 than values predicted based on single compounds. At 50\% observed cytotoxicity of M3, 13-fold less Cd and 6-fold less As were required to achieve the same 50\% cytotoxicity predicted based on single compounds.

\section{Genotoxic mechanisms of action of heavy metals found in mixtures}

Heavy metals present in mixtures induce $\gamma H 2 A X$ based on generation of oxidative stress. Next, we investigated the DNA damage mechanism of action of the mixtures. For this purpose, we checked 
the formation of ROS and subsequent oxidative DNA damage in HepG2 cells treated with noncytotoxic concentrations of M1 and M3 mixtures (i.e. the highest concentration of 250 and $100 \mu \mathrm{M}$ for M1 and M3, receptively) with and without treatment with BSO (antioxidant cell capacity depletion) or NAC (antioxidant cell capacity increase). Using the positive control oxidative stress inducer menadione (MD), we observed as expected a statistically significant increase (1.6-fold) in ROS formation compared to control (Figure $4 \mathbf{a}$-b) and DNA damage (1.9-fold) (Figure 4 c-d). Pre-treatment of the cells with NAC inhibited these two effects and conversely, BSO increased the effect of MD. As with positive control MD, treatment with BSO increased the intracellular ROS and DNA damage induced by M1 and M3, whereas these effects were inhibited by pre-treatment with antioxidant NAC. Furthermore, the survival rates of HepG2 cells increased in both mixtures co-treated with NAC (Appendix 6). We thus demonstrated that M1 and M3 toxic effect might be linked to oxidative DNA damage induction. We also measured the production of ROS after treatment with single heavy metals. The data showed that only As and Cd could generated ROS at the concentration tested (Figure 5).

Heavy metals present in mixtures interact with DNA repair systems. Next, we examined the impact of the mixtures on DNA repair pathways. For this purpose, we pre-treated cells for $1 \mathrm{~h}$ with a specific oxidative stress inducer $\left(\mathrm{KBrO}_{3}\right)$ resulting in oxidative DNA damage specifically repaired by the base excision repair (BER) pathway. $\mathrm{KBrO}_{3} 1 \mathrm{~h}$ treatment triggered as expected a significant $\gamma \mathrm{H} 2 \mathrm{AX}$ induction (1.6-fold) (Figure 6). After washing out and 23h recovery, all oxidative DNA damage were repaired, as revealed by basal $\gamma \mathrm{H} 2 \mathrm{AX}$ level (1.1-fold). Since we previously observed that mixtures M1 and M3 by themselves could generated oxidative DNA damage (Figure 4), we tested the inhibition of the BER DNA repair pathway by M1 and M3 in the presence of the antioxidant NAC (Figure 6) to abolished oxidative DNA damage induced by the mixtures. With both M1 and M3 mixtures (Figure 6), DNA damage was not observed in cells treated with mixtures in presence of NAC, but DNA damage increased when cells were pre-treated with $\mathrm{KBrO}_{3}$ and then treated with 
282 mixtures in presence of NAC. These results demonstrated that the BER DNA repair pathway was

283 probably inhibited by M1 and M3 mixtures. We then tested the effect of the mixtures on the possible 284 inhibition of another DNA repair pathway: the nucleotide excision DNA repair (NER). For this 285 purpose, in a same way than for BER inhibition experiment, cells were treated with BaP, an inducer 286 of bulky DNA adducts specifically repaired by the NER DNA repair pathway (Appendix 7). In co287 treatment experiments, $\mathrm{BaP}(0.3 \mu \mathrm{M})$ plus $\mathrm{M} 1$ or $\mathrm{M} 3$ in the presence of NAC (to avoid oxidative 288 DNA damage induced by mixtures), no significant modification of the $\gamma \mathrm{H} 2 \mathrm{AX}$ induction (2-fold) 289 was observe compared to $\mathrm{BaP}$ alone. These data suggest that neither mixture disturbed the NER 290 DNA repair pathway. 
In the current study, we addressed the combined toxic effects of two complex mixtures present in the French diet, using a comprehensive integrated approach. In 2012, the European Commission published a communication on the combined effects of chemicals, expressing concerns about the current limitations related to assessing compounds individually, and proposing a way forward to ensure that risks associated with chemical mixtures are properly understood and assessed (34). We examined the opportunities for addressing some of the other knowledge gaps, in particular those related to (i) identifying the chemical substances that are the main drivers of mixture toxicity (ii) predicting interactions using mathematical models, and (iii) providing detailed information on the mode of action for a better understanding of the observed toxic effects but also the interactions between each of the individual compounds $(5,8,38)$.

To identify substances that drive toxicity of the mixtures, a "reduced approach" was used on the M1 and M3 mixtures using the ICW $\gamma \mathrm{H} 2 \mathrm{AX}$ assay in HepG2 cells. As described, two sub-mixture phases of each whole mixture were examined separately (e.g. compounds soluble in pure water or in DMSO, respectively), according to the chemical properties of the components present in the mixtures $(26,27)$. Each mixture induced a very similar toxic response than their respective water phase, meaning that the chemicals present in the DMSO phase were not involved in the potential interactions. Heavy metals are considered as major chemical contaminants of the food chain and have been classified as "known" or "probable" human carcinogens by US EPA and IARC $(39,40)$. Actions and interactions between heavy metals are commonly investigated in the context of multiexposure through the environment (41-43). The genotoxicity of heavy metals in co-exposure has been investigated, but recent studies showed synergistic, antagonistic or additive effects both in vivo and in vitro, suggesting that interaction patterns between heavy metals could be difficult to predict (44-49). These discrepancies may result from proportion of the tested compounds in the mixture 
and the end-points tested. The strength of the present study is that mixture composition, and proportion of each component, reflected a realistic exposure.

The next step of our reduced approach showed that the toxic effects of the mixtures were driven by only two heavy metals per mixture: Te and $\mathrm{Cd}$ in $\mathrm{M} 1$, As and $\mathrm{Cd}$ in $\mathrm{M} 3$. Contamination by mixtures of heavy metals frequently occurs in the environment due to increased industrial and anthropogenic activities. The European Food Safety Authority (EFSA) reported that foodstuffs are the primary source of $\mathrm{Cd}$ exposure for the general population, mainly through contamination of cereal products (50,51). Regarding inorganic arsenic, the US Food and Drug Administration reported that rice contains a higher level of As than other foods. Although little information is available on levels of Te in food, consumers may be exposed through butter every day. The genotoxic effects of As, Cd and Te have been demonstrated using in vitro models (28,52-54). Various mechanisms are associated with the genotoxicity of $\mathrm{As}, \mathrm{Cd}$ and $\mathrm{Te}$, including generation of free radicals, oxidative stress and the inhibition of DNA repair pathways (39).

Our previous study classified As, Cd and Te among the most genotoxic metals tested (28). However, based on their concentrations present in the mixtures studied, and on the LOEC determined for each metal, no mixture was expected to induced DNA damage $(26,27)$. On the opposite, whole M1, M3 and their respective binary mixtures induced a similar level of genotoxicity and cytotoxicity. Our mathematical model results based on cytotoxicity data suggest that As, Cd and Te could act jointly and deviate from the additive effect, suggesting mainly a supra-additive effect in mixtures. To confirm the combined effects of mixtures, the cytotoxicity of As, $\mathrm{Cd}$ and $\mathrm{Te}$ was assessed using different conceptual models. Concentration addition (CA) and independent action (IA) models of additivity revealed the absence of overlap between the measured and predicted cytotoxicity curves, and showed that the response of mixtures deviated significantly from a cumulative effect (55). To confirm synergism, we applied the combination index-isobologram approach based on medianeffect equations. The combination index values pointed to an synergic effect of the two binary 
mixtures (37). These results confirmed the measured effects and support the conclusion of a synergistic interaction with the mixtures $(56,57)$.

The sensitive marker of DNA damage $(\gamma \mathrm{H} 2 \mathrm{AX})$ used in this study can originate from various types of DNA damage (e.g. bulky DNA adducts, oxidative DNA lesions). When dealing with multiple chemicals, in vitro approaches are recommended to clarify the mode of action of mixtures and to elucidate the biochemical and physiological events that cause genotoxicity $(9,58)$. First, we checked if the mixtures induced oxidative stress, and therefore caused oxidative DNA damage $(59,60)$. A significant decrease in oxidative stress and $\gamma \mathrm{H} 2 \mathrm{AX}$ induced by mixtures was observed in NACcotreated cells. In contrast, mixture treatments of cells pre-treated with BSO demonstrated a significant increase in these two endpoints. As and Cd, the two drivers of M3, are known to rapidly induce ROS and GSH depletion in cells $(61,62)$. It is therefore reasonable to conclude that DNA damage induced by As and Cd was due to oxidative stress. Like the toxic effects of M3, those of M1 depend on two heavy metals, $\mathrm{Cd}$ and Te. Although Cd could generate ROS, the role of Te contribution in mixture effect is not as clear since Te did not cause oxidative stress in our study, in agreement with previously published results $(28,53,27,52)$.

Secondly, we hypothesized that the observed synergistic genotoxic effect of mixtures may be linked to inhibition of DNA repair pathways. Indeed, our data demonstrated that M1 and M3 mixtures could inhibit the BER DNA repair pathway but not the NER pathway. Hence, all the results of the in vitro approaches used in the current study converge to show that the observed synergism in the genotoxic effects of the mixtures may be linked with the mode of action of the different heavy metals. Some heavy metals present in the mixtures, such as $\mathrm{Cd}$ and As, are able to induce ROS production that induced oxidative DNA damage. At the same time, $\mathrm{Cd}$ and As, as well as Te, may affect the specific repair pathway (BER) involved in the repair of oxidative DNA damage. Therefore, binary mixtures could induced a substantial biological response, while the individual chemicals are found to be inactive at similar concentrations. 
In summary, we investigated the toxic effect of chemical mixtures present in the French diet using

366 an original approach based on a combination of cellular and molecular experiments and

367 mathematical analysis. We showed that heavy metals were the main drivers of the toxicity induced

368 by mixtures with a strong synergism. New analyses should be perform to elucidate whether or not

369 the concentrations tested in our study are relevant under realistic exposure conditions. However, the

370 strength of the present study is that mixture composition, and proportion of each component,

371 reflected a realistic exposure and is a proof of principle of the toxic effect of food contaminants in

372 mixture. Exploring the mechanisms involved in the combined genotoxic effect of these mixtures

373 leads us to hypothesize that both induction of oxidative DNA damage and suppression of their repair

374 contribute to the observed synergistic effects. This conclusion should be take into careful

375 consideration in environmental toxicology and chemical risk assessment. 
B. Kopp was supported by a doctoral fellowship from INRA and ANSES.

\section{Conflict of interest statement}

379 The authors declare no competing interests.

\section{Author contributions}

381

382

Supplementary Data 7. Effect of mixtures on the repair of DNA damage induced by benzo[a]pyrene 395

B.K. performed most of the experiments, data analysis and interpretation through discussions with L.L.H. and M.A.. B.K., P.S. and A-K.I. performed statistical analyses. M.A. planned and supervised the project. The manuscript was written by B.K. All the authors discussed the results and contributed to editing of the manuscript.

\section{Supporting Information}

Supplementary Data 1. Composition of the different heavy metal M1 sub-mixtures tested.

Supplementary Data 2. Composition of the different heavy metal M3 sub-mixtures tested.

Supplementary Data 3. Cytotoxicity of different mixtures in HepG2 cells measured using the ICW technique.

Supplementary Data 4. Cytotoxicity of arsenic, cadmium and tellurium in HepG2 cells.

Supplementary Data 5. DRI values calculated for binary mixtures.

Supplementary Data 6. Cytotoxicity of mixtures in HepG2 cells co-treated with antioxidant and prooxidant. in HepG2 cells. 


\section{References}

1. ANSES (2011) Second Total Diet Studies.

2. Efsa (2016) Chemicals in Food 2016: Overview of selected data collection.

3. Fao/Who (2005) Dietary Exposure Assessment of Chemicals in Food.

4. Traore, T., Bechaux, C., Sirot, V., and Crepet, A. (2016) To which chemical mixtures is the French population exposed? Mixture identification from the second French Total Diet Study. Food Chem Toxicol, 98, 179-188.

5. Kortenkamp, A. (2009) State of the Art Report on Mixture Toxicity. http://ec.europa.eu/environment/chemicals/effects/pdf/report_mixture_toxicity.pdf.

6. Hernandez, A.F., Gil, F., and Lacasana, M. (2017) Toxicological interactions of pesticide mixtures: an update. Arch Toxicol, 91, 3211-3223.

7. Hadrup, N., Taxvig, C., Pedersen, M., Nellemann, C., Hass, U., and Vinggaard, A.M. (2013) Concentration addition, independent action and generalized concentration addition models for mixture effect prediction of sex hormone synthesis in vitro. PLoS One, 8, e70490.

8. Cedergreen, N., Sørensen, H., and Svendsen, C. (2012) Can the joint effect of ternary mixtures be predicted from binary mixture toxicity results? Science of The Total Environment, 427-428, 229-237.

9. Efsa (2013) International Frameworks Dealing with Human Risk Assessment of Combined Exposure to Multiple Chemicals.

10. Kienzler, A., Bopp, S.K., van der Linden, S., Berggren, E., and Worth, A. (2016) Regulatory assessment of chemical mixtures: Requirements, current approaches and future perspectives. Regul Toxicol Pharmacol, 80, 321-334.

11. Loewe, S. (1947) Bioassay by Direct Potency Estimation. Science, 106, 89-91.

12. Bliss, C.I. (1939) The toxicity of poisons applied jointly. Annals of Applied Biology, 26, 585-615.

13. Altenburger, R., Nendza, M., and Schüürmann, G. (2003) Mixture toxicity and its modeling by quantitative structure-activity relationships. Environ. Toxicol. Chem., 22, 1900-1915.

14. Backhaus, T., and Faust, M. (2012) Predictive environmental risk assessment of chemical mixtures: a conceptual framework. Environ Sci Technol, 46, 2564-2573.

15. Monosson, E. (2005) Chemical mixtures: considering the evolution of toxicology and chemical assessment. Environ Health Perspect, 113, 383-390.

16. Carpenter, D.O., Arcaro, K., and Spink, D.C. (2002) Understanding the human health effects of chemical mixtures. Environ. Health Perspect., 110 Suppl 1, 25-42. 
17. Ec (2011) Toxicity and Assessment of Chemical Mixtures.

18. Orton, F., Ermler, S., Kugathas, S., Rosivatz, E., Scholze, M., and Kortenkamp, A. (2014) Mixture effects at very low doses with combinations of anti-androgenic pesticides, antioxidants, industrial pollutant and chemicals used in personal care products. Toxicol Appl Pharmacol, 278, 201-208.

19. Boobis, A., Budinsky, R., Collie, S., Crofton, K., Embry, M., Felter, S., Hertzberg, R., Kopp, D., Mihlan, G., Mumtaz, M., Price, P., Solomon, K., Teuschler, L., Yang, R., and Zaleski, R. (2011) Critical analysis of literature on low-dose synergy for use in screening chemical mixtures for risk assessment. Crit. Rev. Toxicol., 41, 369-383.

20. Cedergreen, N. (2014) Quantifying Synergy: A Systematic Review of Mixture Toxicity Studies within Environmental Toxicology. PLoS One, 9.

21. Roell, K.R., Reif, D.M., and Motsinger-Reif, A.A. (2017) An Introduction to Terminology and Methodology of Chemical Synergy-Perspectives from Across Disciplines. Front Pharmacol, 8, 158.

22. Alassane-Kpembi, I., Schatzmayr, G., Taranu, I., Marin, D., Puel, O., and Oswald, I.P. (2017) Mycotoxins co-contamination: Methodological aspects and biological relevance of combined toxicity studies. Critical reviews in food science and nutrition, 57, 3489-3507.

23. Ferron, P.-J., Dumazeau, K., Beaulieu, J.-F., Le Hégarat, L., and Fessard, V. (2016) Combined Effects of Lipophilic Phycotoxins (Okadaic Acid, Azapsiracid-1 and Yessotoxin) on Human Intestinal Cells Models. Toxins (Basel), 8.

24. Lasch, A., Lichtenstein, D., Marx-Stoelting, P., Braeuning, A., and Alarcan, J. (2020) Mixture effects of chemicals: The difficulty to choose appropriate mathematical models for appropriate conclusions. Environmental pollution, 260, 113953.

25. Backhaus, T., Gustavsson, M., and Yngsell, D. (2015) Mixture toxicity contribution of emerging and legacy contaminants in environmental monitoring data from Norway.

26. Kopp, B., Le Hégarat, L., and Audebert, M. (2020) Differential toxic effects of food contaminant mixtures in HepaRG cells after single or repeated treatments. Mutation Research/Genetic Toxicology and Environmental Mutagenesis, 850-851, 503161.

27. Kopp, B., Vignard, J., Mirey, G., Fessard, V., Zalko, D., Le Hgarat, L., and Audebert, M. (2018) Genotoxicity and mutagenicity assessment of food contaminant mixtures present in the French diet. Environ Mol Mutagen, 59, 742-754.

28. Kopp, B., Zalko, D., and Audebert, M. (2018) Genotoxicity of 11 heavy metals detected as food contaminants in two human cell lines. Environ Mol Mutagen, 59, 202-210. 
29. Audebert, M., Dolo, L., Perdu, E., Cravedi, J.P., and Zalko, D. (2011) Use of the $\gamma \mathrm{H} 2 \mathrm{AX}$ assay for assessing the genotoxicity of bisphenol A and bisphenol $\mathrm{F}$ in human cell lines. Arch Toxicol, 85, 1463-1473.

30. Chevereau, M., Glatt, H., Zalko, D., Cravedi, J.P., and Audebert, M. (2017) Role of human sulfotransferase $1 \mathrm{~A} 1$ and $\mathrm{N}$-acetyltransferase 2 in the metabolic activation of 16 heterocyclic amines and related heterocyclics to genotoxicants in recombinant V79 cells. Arch Toxicol, 91, 3175-3184.

31. Graillot, V., Takakura, N., Hegarat, L.L., Fessard, V., Audebert, M., and Cravedi, J.-P. (2012) Genotoxicity of pesticide mixtures present in the diet of the French population. Environ. Mol. Mutagen., 53, 173-184.

32. Graillot, V., Tomasetig, F., Cravedi, J.-P., and Audebert, M. (2012) Evidence of the in vitro genotoxicity of methyl-pyrazole pesticides in human cells. Mutat. Res., 748, 8-16.

33. Khoury, L., Zalko, D., and Audebert, M. (2016) Complementarity of phosphorylated histones $\mathrm{H} 2 \mathrm{AX}$ and $\mathrm{H} 3$ quantification in different cell lines for genotoxicity screening. Arch Toxicol, 90, 1983-1995.

34. Ec (2012) Communication from the Commission to the Council - the combination effects of chemicals.

35. Chou, T.C. (2010) Drug Combination Studies and Their Synergy Quantification Using the Chou-Talalay Method. Cancer Research, 70, 440-446.

36. Kopp, B., Khoury, L., and Audebert, M. (2019) Validation of the gammaH2AX biomarker for genotoxicity assessment: a review. Arch Toxicol, 93, 2103-2114.

37. Chou, T.C., and Talalay, P. (1984) Quantitative analysis of dose-effect relationships: the combined effects of multiple drugs or enzyme inhibitors. Adv. Enzyme Regul., 22, 27-55.

38. Meek, M.E., Boobis, A.R., Crofton, K.M., Heinemeyer, G., Raaij, M.V., and Vickers, C. (2011) Risk assessment of combined exposure to multiple chemicals: A WHO/IPCS framework. Regul Toxicol Pharmacol.

39. Beyersmann, D., and Hartwig, A. (2008) Carcinogenic metal compounds: recent insight into molecular and cellular mechanisms. Arch Toxicol, 82, 493.

40. Kim, H.S., Kim, Y.J., and Seo, Y.R. (2015) An Overview of Carcinogenic Heavy Metal: Molecular Toxicity Mechanism and Prevention. Journal of cancer prevention, 20, 232-240.

41. Kutrowska, A., Malecka, A., Piechalak, A., Masiakowski, W., Hanc, A., Baralkiewicz, D., Andrzejewska, B., Zbierska, J., and Tomaszewska, B. (2017) Effects of binary metal combinations on zinc, copper, cadmium and lead uptake and distribution in Brassica juncea. 
Journal of trace elements in medicine and biology : organ of the Society for Minerals and Trace Elements, 44, 32-39.

42. Shen, G., Lu, Y., and Hong, J. (2006) Combined effect of heavy metals and polycyclic aromatic hydrocarbons on urease activity in soil. Ecotoxicology and environmental safety, 63, 474-480.

43. Uwizeyimana, H., Wang, M., Chen, W., and Khan, K. (2017) The eco-toxic effects of pesticide and heavy metal mixtures towards earthworms in soil. Environmental toxicology and pharmacology, 55, 20-29.

44. Karri, V., Kumar, V., Ramos, D., Oliveira, E., and Schuhmacher, M. (2018) An in vitro cytotoxic approach to assess the toxicity of heavy metals and their binary mixtures on hippocampal HT-22 cell line. Toxicol Lett, 282, 25-36.

45. Lin, X., Gu, Y., Zhou, Q., Mao, G., Zou, B., and Zhao, J. (2016) Combined toxicity of heavy metal mixtures in liver cells. Journal of applied toxicology : JAT, 36, 1163-1172.

46. Lu, C., Svoboda, K.R., Lenz, K.A., Pattison, C., and Ma, H. (2018) Toxicity interactions between manganese $(\mathrm{Mn})$ and lead $(\mathrm{Pb})$ or cadmium $(\mathrm{Cd})$ in a model organism the nematode C. elegans. Environ Sci Pollut Res Int, 25, 15378-15389.

47. Muthusamy, S., Peng, C., and Ng, J.C. (2016) The binary, ternary and quaternary mixture toxicity of benzo[a]pyrene, arsenic, cadmium and lead in HepG2 cells. Toxicol Res (Camb), 5, 703-713.

48. Valeri, L., Mazumdar, M.M., Bobb, J.F., Claus Henn, B., Rodrigues, E., Sharif, O.I.A., Kile, M.L., Quamruzzaman, Q., Afroz, S., Golam, M., Amarasiriwardena, C., Bellinger, D.C., Christiani, D.C., Coull, B.A., and Wright, R.O. (2017) The Joint Effect of Prenatal Exposure to Metal Mixtures on Neurodevelopmental Outcomes at 20-40 Months of Age: Evidence from Rural Bangladesh. Environ Health Perspect, 125, 067015.

49. Zhu, H., Jia, Y., Cao, H., Meng, F., and Liu, X. (2014) Biochemical and histopathological effects of subchronic oral exposure of rats to a mixture of five toxic elements. Food Chem Toxicol, 71, 166-175.

50. Chunhabundit, R. (2016) Cadmium Exposure and Potential Health Risk from Foods in Contaminated Area, Thailand. Toxicol Res, 32, 65-72.

51. Efsa (2009) Cadmium in food - Scientific opinion of the Panel on Contaminants in the Food Chain. EFSA Journal, 7, n/a-n/a.

52. Faita, F., Cori, L., Bianchi, F., and Andreassi, M. (2013) Arsenic-Induced Genotoxicity and Genetic Susceptibility to Arsenic-Related Pathologies. International Journal of Environmental Research and Public Health, 10, 1527-1546. 
53. Sandoval, J.M., Leveque, P., Gallez, B., Vasquez, C.C., and Buc Calderon, P. (2010) Tellurite-induced oxidative stress leads to cell death of murine hepatocarcinoma cells. Biometals : an international journal on the role of metal ions in biology, biochemistry, and medicine, 23, 623-632.

54. Skipper, A., Sims, J.N., Yedjou, C.G., and Tchounwou, P.B. (2016) Cadmium Chloride Induces DNA Damage and Apoptosis of Human Liver Carcinoma Cells via Oxidative Stress. Int J Environ Res Public Health, 13.

55. Rajapakse, N., Silva, E., Scholze, M., and Kortenkamp, A. (2004) Deviation from additivity with estrogenic mixtures containing 4-nonylphenol and 4-tert-octylphenol detected in the ESCREEN assay. Environ Sci Technol, 38, 6343-6352.

56. Chou, T.C. (2006) Theoretical Basis, Experimental Design, and Computerized Simulation of Synergism and Antagonism in Drug Combination Studies. Pharmacol. Rev., 58, 621-681.

57. Foucquier, J., and Guedj, M. (2015) Analysis of drug combinations: current methodological landscape. Pharmacol Res Perspect, 3.

58. Boobis, A.R., Doe, J.E., Heinrich-Hirsch, B., Meek, M.E.B., Munn, S., Ruchirawat, M., Schlatter, J., Seed, J., and Vickers, C. (2008) IPCS framework for analyzing the relevance of a noncancer mode of action for humans. Crit. Rev. Toxicol., 38, 87-96.

59. Reuter, S., Gupta, S.C., Chaturvedi, M.M., and Aggarwal, B.B. (2010) Oxidative stress, inflammation, and cancer: how are they linked? Free radical biology \& medicine, 49, 16031616.

60. Schieber, M., and Chandel, N.S. (2014) ROS function in redox signaling and oxidative stress. Current biology : $C B, \mathbf{2 4}, \mathrm{R} 453-462$.

61. Kim, Y., Jeong, I.G., You, D., Song, S.H., Suh, N., Jang, S.W., Kim, S., Hwang, J.J., and Kim, C.S. (2014) Sodium meta-arsenite induces reactive oxygen species-dependent apoptosis, necrosis, and autophagy in both androgen-sensitive and androgen-insensitive prostate cancer cells. Anti-cancer drugs, 25, 53-62.

62. Oh, S.H., and Lim, S.C. (2006) A rapid and transient ROS generation by cadmium triggers apoptosis via caspase-dependent pathway in HepG2 cells and this is inhibited through $\mathrm{N}$ acetylcysteine-mediated catalase upregulation. Toxicol Appl Pharmacol, 212, 212-223. 
559

560

561

562

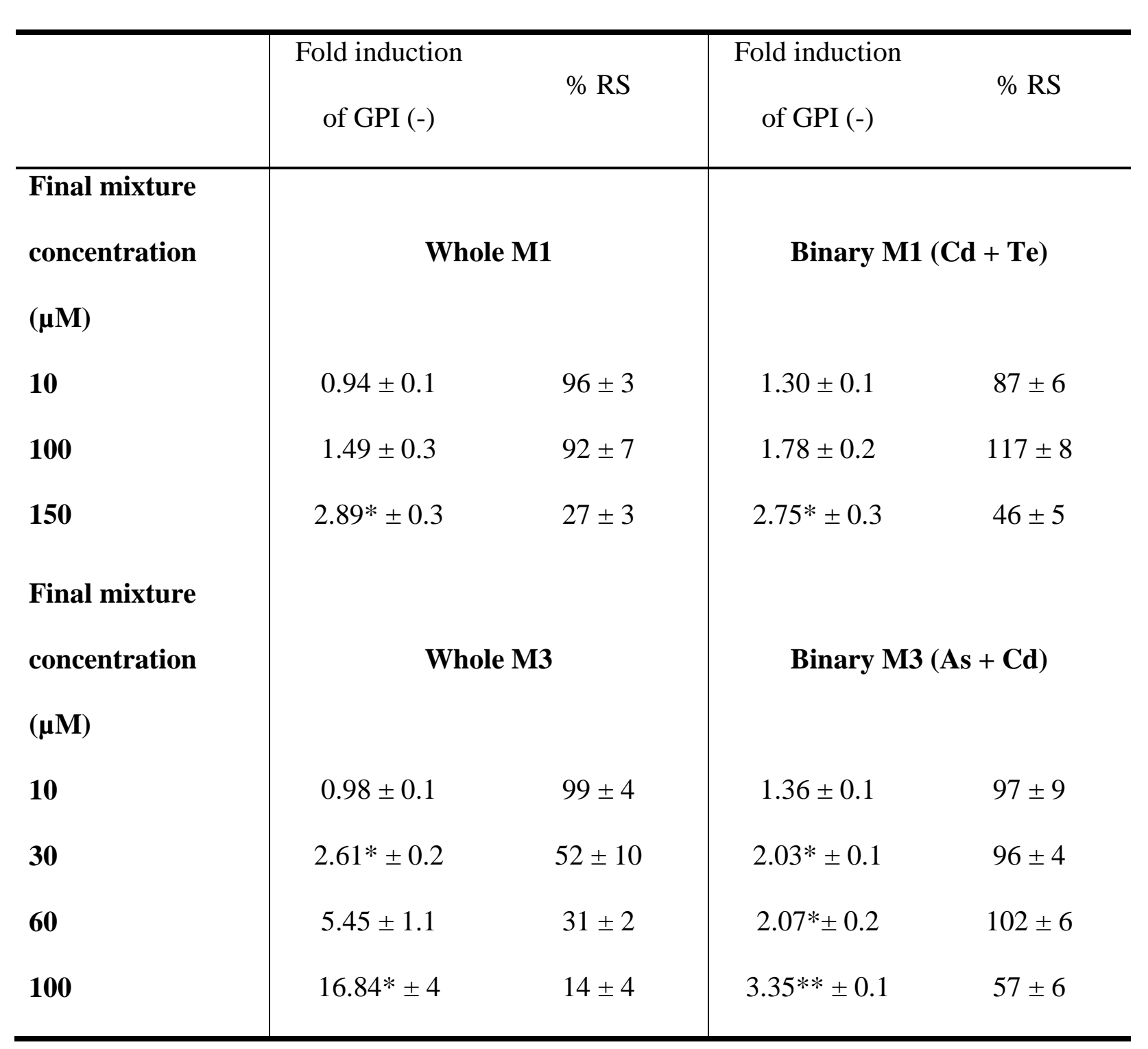

Table 1. PIG-A mutation frequency in response to mixtures (whole versus binary) treatment in HepG2 cells. Fold induction of GPI (-) and \% of relative survival (\% RS) were normalized with their vehicle. Each value represents the mean \pm SEM $(n>3)$. Significant differences with control are $\operatorname{noted}(* \mathrm{p} \leq 0.05 ; * \mathrm{*} \leq 0.01)$ 


\section{Figure legends}

Figure 1. Effects of whole mixtures and their respective water and DMSO phases on the phosphorylation of $\mathrm{H2AX}$ in HepG2 cells. Cells were treated with whole mixtures or their respective DMSO and water phases at $100 \mu \mathrm{M}$ for $24 \mathrm{~h}$ then genotoxicity (histogram) and cell viability were analyzed (square). (a). Mixture 1. (b). Mixture 3. Each value represents the mean of 6 independent experiments and $a, p<0.05 ; b, p<0.01 ; c, p<0.001$ indicated statistical significance between matched groups.

Figure 2. Effects of heavy metal combinations corresponding to each mixture on the phosphorylation of H2AX in HepG2 cells. Different combinations of each mixture (whole, only the water phase containing heavy metals or sub-mixtures of heavy metals (Appendix 1 and 2)) were test at $100 \mu \mathrm{M}$ at proportion corresponding to their proportions in the French diet. Genotoxicity (histogram) and cell viability were analyzed (square) was estimated after $24 \mathrm{~h}$ treatment and compared to vehicle controls. Combinations for M1 (a), combinations for M3 (b). Each value represents the mean of 5 independent experiments and significant differences compared to the vehicle control are noted $\left(* p \leq 0.05 ;{ }^{* *} p \leq 0.01 ;{ }^{* * *} p \leq 0.001\right)$. Binary combinations of the heavy metals main drivers for M1 (c) and M3 (d) at $100 \mu \mathrm{M}$ for $24 \mathrm{~h}$ were compared to their associated mixtures (water phase without the two heavy metals main drivers and whole mixture). Each value represents the mean of 5 independent experiments and $a, p<0.05 ; b, p<0.01 ; c, p<0.001$ indicated statistical significance between matched groups.

Figure 3. Predicted cytotoxic effects of mixtures. Combination index (CI)-fraction affected ( $f a)$ curves were obtained from individual data obtained $\pm 95 \%$ confidence intervals $(n>3)$ based on SDA 
using the CompuSyn software $(\mathbf{a}, \mathbf{b})$. Horizontal lines correspond to lower and upper limits of the additivity zone.

Figure 4. ROS production and genotoxicity induced by mixtures co-treated with antioxidant (NAC) and pro-oxidant (BSO) in HepG2 cells. The fold induction of intracellular ROS production $(\mathbf{a}, \mathbf{b})$ in cells was detected by $\mathrm{CM}-\mathrm{H}_{2}$ DCFDA fluorescence intensity and genotoxicity $(\mathbf{c}, \mathbf{d})$ was quantified with the $\gamma \mathrm{H} 2 \mathrm{AX}$ biomarker. MD, menadione, positive control of oxidative stress induction. Each value represents the mean $\pm \operatorname{SEM}(\mathrm{n}=6) * p \leq 0.05 ; * * p \leq 0.01 ; * * * p \leq 0.001$ indicated statistical significance from control DMSO, and $a, p<0.05 ; b, p<0.01 ; c, p<0.001$ indicated statistical significance between matched groups (medium, NAC, BSO).

Figure 5. ROS production induced by individual heavy metals in HepG2 cells. The fold induction of intracellular ROS was quantify through $\mathrm{CM}-\mathrm{H}_{2}$ DCFDA fluorescence intensity compared to control after $24 \mathrm{~h}$ treatment. Each value represents the mean $\pm \operatorname{SEM}(\mathrm{n}=5) .{ }^{*} p \leq 0.05 ; * * p \leq 0.01$; $* * * p \leq 0.001$ indicated statistical significance from negative control.

Figure 6. Effect of mixtures on the repair of oxidative DNA damage induced by potassium bromate in HepG2 cells. Cells we pre-treated for $1 \mathrm{~h}$ with a specific oxidative stress inducer (KBrO3) resulting in oxidative DNA damage ( $\gamma \mathrm{H} 2 \mathrm{AX}$ induction) specifically repaired by the base excision repair (BER) pathway during the $23 \mathrm{~h}$ recovery (return to basal $\gamma \mathrm{H} 2 \mathrm{AX}$ level). Since we previously observed that mixtures M1 and M3 by themselves could generated oxidative DNA damage, inhibition of the BER DNA repair pathway by M1 and M3 was tested in the presence of the antioxidant NAC. The level of DNA damage in cells pre-treated with $\mathrm{KBrO}_{3}(1 \mathrm{mM})$ for 1-hr before 
613 incubation with M1 (a) or M3 (b) with and without NAC for 23-hr recovery period was evaluated 614 using the ICW $\gamma \mathrm{H} 2 \mathrm{AX}$ assay. Each value represents the mean $\pm \operatorname{SEM}(\mathrm{n}=4) .{ }^{*} p \leq 0.05 ; * * p \leq 0.01$; $615 * * * p \leq 0.001$ indicate statistical significance from control DMSO, and $a, p<0.05 ; b, p<0.01 ; c, p$ $616<0.001$ indicate statistical significance between matched groups (medium, NAC, $\mathrm{NAC}$ and $\mathrm{KBrO}_{3}$ ). 